\title{
A representatividade da união homossexual e a formação familiar na propaganda “Sophia” do Mercado Livre sob a perspectiva de um grupo focal
}

\author{
(The representativeness of homosexual union and family formation in \\ Mercado Livre's "Sophia” propaganda from the perspective of a focus group) \\ (La representatividad de la unión homosexual y la formación de la familia en el anuncio \\ "Sophia", de Mercado Libre, bajo una perspectiva de grupo focal) \\ Marta $\operatorname{Brod}^{1}$ \\ Camila Santos de Souza ${ }^{2}$
}

RESUMO: Entre os diversos problemas sociais atualmente discutidos, a diversidade é um tema de extrema importância, sobretudo em um contexto de intolerância em relação a minorias, como é o contexto moderno. Com o intuito de promover a inclusão, este estudo busca compreender a percepção e opinião das pessoas sob vários pontos de vista acerca de novas configurações familiares, em particular a união homossexual, sendo princípio de estudo a propaganda "Sophia”, lançada na ocasião do Dia Das Mães de 2018 pelo Mercado Livre. Para isto, utilizou-se como técnica o grupo focal formado por pessoas de variadas idades, gêneros e religiões. O comercial foi exibido ao grupo e, em seguida, foram feitos questionamentos a respeito do tema por meio de uma entrevista semiestruturada e coletiva. Durante a conversa, algumas opiniões em comum ganharam destaque, como a falta de representação de personagens homossexuais em comerciais diversos e a vigência da heteronormatividade, o que fez com que a maioria dos(as) participantes não imaginasse que a propaganda tratasse de uma família não convencional.

PALAVRAS-CHAVE: Família. Comercial. Diversidade. Inclusão.

\begin{abstract}
Among the countless social issues currently discussed, diversity is a critical theme, especially in a context of intolerance towards minorized social groups such as is the contemporaneity. In an attempt to promote inclusion, this study seeks to understand different perceptions and opinions regarding new family configurations, in particular, the homosexual union. To this end, the 2018 Mothers' Day campaign entitled "Sophia," launched by the Brazilian company Mercado Livre, was shown to a focus group formed by people of different ages, genders, and religions. Guided by a semi-structured and collective interview, participants answered a series of questions about the theme. Some opinions were highlighted during the conversation, such as the lack of representation of homosexual characters in various commercials and the prevailing heteronormativity, so that most participants could not grasp that the advertisement depicted an unconventional family.

Keywords: Family. Propaganda. Diversity. Inclusion.
\end{abstract}

Resumen: Entre los problemas sociales que se discuten actualmente, la diversidad es un tema importante, sobre todo en los tiempos actuales de intolerancia hacia las minorías. Con el fin de promover la inclusión, este estudio pretende

1 UniSociesc Blumenau. E-mail: martabrod@gmail.com.

2 UniSociesc Blumenau. E-mail: camila63santos@gmail.com. 
comprender la percepción y opinión de las personas, sus diversos puntos de vista, sobre las nuevas configuraciones familiares, en particular la unión homosexual, tomando como objeto de estudio el anuncio "Sophia”, una campaña del Mercado Libre para el Día de la Madre del año 2018. Para ello, se empleó la técnica de grupo focal conformado por personas de diferentes edades, géneros y religiones. Se mostró el anuncio al grupo, y luego se hicieron preguntas sobre el tema a través de una entrevista semiestructurada y colectiva. Durante la conversación se destacaron algunas opiniones en común, como la falta de representación de personajes homosexuales en varios anuncios y el discernimiento de heteronormatividad, lo que hizo que la mayoría de los participantes no imaginaran que el anuncio "Sophia" trataba una familia poco convencional.

Palabras clave: Familia. Anuncio. Diversidad. Inclusión.

\section{Introdução}

Em virtude das recentes mudanças e avanços da sociedade sobre o aspecto de opiniões e pensamentos, faz-se necessário refletir sobre como podemos contribuir para um mundo mais justo e igualitário. Assim como todo cidadão e cidadã tem o dever ético de respeitar as diferenças, com a publicidade não é diferente. Trabalhando cada vez mais para fortalecer uma imagem consciente, mesmo que seja com interesses econômicos, as propagandas estão seguindo em direção aos avanços da sociedade, traçando um novo e longo caminho, trazendo à tona uma forte presença do público $\mathrm{LGBT}^{3}{ }^{3}$, o que pode ser visto na aparição, nesse contexto, de novas relações familiares, tema abordado neste trabalho.

Desde 2011, a união civil estável entre pessoas do mesmo gênero foi reconhecida no Brasil. Mesmo que tardia, essa decisão colaborou para o reconhecimento de que pessoas do mesmo gênero podem constituir uma família, contribuindo para a desmistificação do conceito de família e abandonando a ideia de que o núcleo familiar possa ser formado única e exclusivamente por um homem, uma mulher e seus filhos. De acordo com Dias (2005), todos os vínculos que tenham como base a afetividade, amor e companheirismo devem ser reconhecidos como família, pois esse conceito vai muito além do que se refere ao biológico. Uma união formada por pessoas do mesmo gênero, assim como todas as outras, merece a proteção do estado. Temas como este ainda causam polêmicas e desconforto pela parte intolerante da sociedade contemporânea, assim, cabe à comunicação discutir tal diversidade e contribuir para a proliferação da informação, além de causar reflexão e discussões o tema, para que este seja visto pelas pessoas com a naturalidade e respeito que merece.

A propaganda analisada, "Sophia”4, é uma campanha de Dia Das Mães do Mercado Livre publicada em 2018 no YouTube e tem como foco as diferentes formas de se constituir uma família. O vídeo trata de uma adolescente que parece contradizer sua fala em vários momentos ao descrever a personalidade de sua mãe, citando-a de diversas maneiras durante a

3 Utilizaremos durante todo o estudo a sigla LGBT+ em vez, por exemplo, de LGBTTTIQA+ (lésbicas, gays, bissexuais, travestis, transexuais, transgêneros, intersexuais, queer, assexuais e outras possibilidades) por ser a sigla mais em uso por movimentos sociais. Compreendemos que a sigla não contempla toda a gama da sexualidade humana (BRAGANÇA, 2019, p. 527).

4 Vídeo no YouTube da propaganda "Sophia”: https://youtu.be/1XfIR370SRc 
propaganda. No final do vídeo, tudo é esclarecido, uma vez que a adolescente tem duas mães. Com isso, este artigo analisará a campanha tendo em vista a importância de representar novas formações familiares e buscará compreender os sentidos atribuídos ao tema por meio das opiniões e percepções dos(as) participantes do estudo.

Em suma, este artigo tem como foco compreender a opinião e percepção geral da população através de um grupo focal que trata da representação da família constituída pela união entre pessoas do mesmo gênero, tendo como base de pesquisa e análise a propaganda de Dia das Mães “Sophia”, do Mercado Livre. Temos como ponto de partida o enfoque na importância de incluir toda forma de união, família e amor e, ao mesmo tempo, conscientizar a sociedade acerca dessa temática. A escolha dessa propaganda se deve ao fato dela tratar uma família constituída pela união entre pessoas do mesmo gênero de maneira leve e bemhumorada, levando a reflexões acerca da normalidade da família tradicional. A pesquisa foi realizada de forma qualitativa e exploratória, e integraram o grupo focal 10 pessoas entre a idade de 18 a 50 anos de diferentes gêneros, sexo ${ }^{5}$ e religião.

Para isso, subdividiu-se o presente estudo em seis tópicos principais: o primeiro, introdução, trabalhará um conceito inicial sobre o tema e o que será abordado; o segundo apresentará a opinião de diversos autores acerca do tema homossexualidade e mídia que é o fio condutor da pesquisa; o terceiro visa estudar a representação midiática na propaganda junto as empresas, logo em seguida, o tópico apresentará aspectos importantes para se analisar um vídeo. O quarto passa a aprofundar o tema, apontando o método de pesquisa e os procedimentos usados; o quinto tópico, por sua vez, apresentará a análise dos dados apurados; por fim, se conclui todos os tópicos acima apontados.

\section{Homossexualidade e mídia}

Sexualidade é um tabu há muito tempo e pouco a pouco vem se desconstruindo. O desconforto em torno desse assunto se deve ao padrão normativo construído pela sociedade: a heteronormatividade.

Por heteronormatividade entendemos aquelas instituições, estruturas de compreensão e orientações práticas que não apenas fazem com que a heterossexualidade pareça coerente - ou seja, organizada como sexualidade - mas também que seja privilegiada. Sua coerência é sempre provisional e seu privilégio pode adotar várias formas (que às vezes são contraditórias): passa despercebida como linguagem básica sobre aspectos sociais e pessoais; é percebida como um estado natural; também se projeta como um

5 Citados por Nogueira (2001), os autores Gilbert, Hallett e Eldridge (1994) designam "sexo” para classificar a anatomia humana do indivíduo, homem ou mulher, de acordo com seus órgãos genitais. Oliveira e Knöner (2005) evidenciam a fala de Stoller (1993), que, por sua vez, diz que gênero não tem sua comprovação através da biologia, pois indivíduos podem apresentar características ditas femininas ou masculinas sem ter qualquer ligação ao seu sexo. 
objetivo ideal ou moral. (BERLANT; WARNER, 2002, p. 230)

A mídia tem poder de levantar grandes questionamentos e disseminar ideias e opiniões sobre diversos assuntos. Esses assuntos ganham visibilidade com facilidade, e a mídia sempre foi um aliado bom e ruim na formação de opinião de um indivíduo. De acordo com Medrado (2000), a mídia tem papel maior que a circulação e produção de campanhas, sendo também parte de um sistema político que possibilita a reformulação de conteúdos, promovendo novos significados e sentidos. Seguindo essa linha de pensamento,

os discursos veiculados pela mídia acionam poderosos efeitos de verdade, que podem contribuir significativamente para a construção das identidades dos sujeitos. Neste sentido, podemos afirmar que a mídia, especialmente a televisiva, pode ser considerada como um espaço educativo, uma vez que produz conhecimentos a respeito da vida, do mundo que nos cerca, de como devemos ser ou nos comportar, do que devemos gostar. (FELIPE, 2007, p. 4)

Ainda indagando sobre a construção e desconstrução que a mídia exerce sobre os indivíduos,

a mídia é um campo institucional em que o sujeito que nela fala é, ao mesmo tempo, aquele que pode dizer a verdade dos fatos - pelo saber que detém sobre eles - e aquele que pode produzir os fatos na sua verdade e submetê-los à realidade - pelo poder que exerce na sociedade. (NAVARRO, 2010, p. 84)

A mídia tem poder de gerar opiniões constantes acerca de diversos assuntos, e alguns(as) autores(as) refletem sobre o posicionamento da mídia em relação à questão de gênero e sexualidade. Sabe-se que as telenovelas indagam novos pensamentos por representar diversos assuntos, tendo uma forte interação com a população que a consome e engajando grande parte da população, principalmente a brasileira, que, ao longo dos anos, sempre se mostrou um público assíduo de telenovelas. Marques (2003) mostra a presença de personagens homossexuais nas telenovelas brasileiras desde os anos 1970, com maior intensificação do tema nos anos 1980, época em que se teve uma sequência de quatro novelas seguidas feitas na Rede Globo com a temática, exaltando a visibilidade homossexual.

Os avanços da comunicação junto à tecnologia e a busca constante dos meios de comunicação em se atualizar deram visibilidade à causa LGBT+ como novo nicho de mercado, atingindo pessoas com grande poder aquisitivo, o que gerou interesse em se abrir discussões sobre a normalização do assunto. Trevisan (2000) e Nunan (2003) apontam que a inclusão e a promoção da diversidade nos meios de comunicação estão amplamente ligadas a interesses monetários, pois este tema se tornou um produto rentável, a partir do qual pode-se agradar àqueles que buscam outras representações da sociedade, mas, acima de tudo, é uma estratégia para alcançar um novo nicho de consumidores. 
Por maior que sejam os interesses monetários da mídia em discutir o assunto, ainda é de total importância que essa discussão seja cada vez mais frequente. Beck (1997) mostra os avanços das mídias eletrônicas como componentes importantes para avaliar as mudanças nas relações sociais e íntimas. A mídia televisiva tem um dos papéis mais importante na disseminação acerca do tema, visto que este ainda é o meio de comunicação mais acessível à população. Thompson (2004) ressalta que, ao incluir novos temas, a televisão abriu novas portas para o surgimento de organizações e novas respostas de grupos opostos através de informações mediadas.

\section{As representações midiáticas na propaganda e as empresas}

As organizações e a propaganda andam lado a lado, pois é desta forma que a posição da marca junto a sua imagem será definida ao público, assim, faz-se necessário entendermos os conceitos primordiais a respeito da publicidade e propaganda. Segundo Kotler e Keller (2012), define-se propaganda como um método de apresentar um produto, serviço ou ideia de forma paga por um anunciante. Para Alves, Fontoura e Antoniutti (2012), a publicidade tem o intuito de promover a compra, despertando interesse e desejo de adquirir um produto, para então promover o lucro. As autoras definem também propaganda como uma propagação de ideias sem interesse comercial, promovendo a imagem e apelando para o lado emocional do indivíduo. Tavares (2005) cita que o discurso publicitário desfruta das variações da língua do cotidiano para manipular, convencer e remodelar a percepção do público quanto à marca ou ao produto.

Tal exemplo podia ser visto nas propagandas antigas que criavam imagens simbólicas e assemelhavam características desejáveis a pessoas em produtos, criando a necessidade do consumo do determinado produto para ser uma pessoa bem-informada e que se enquadra aos padrões ditados. Por conseguinte, Kellner (2001) ressalta ainda que as propagandas abrangem o cotidiano social do período em que se passa. Do mesmo modo, Arruda (2002) destaca que representações ditadas por meio de anúncios e propagandas impregnam na mente do público visualizações do imaginário que tornam essas representações comuns ao dia a dia das pessoas, fazendo parte da realidade e convivência em sociedade.

Woodward (2000) afirma que essas representações produzem significados que fazem com que os cidadãos entendam as experiências proporcionadas pelas propagandas consumidas de forma a se rotularem como suas protagonistas, chegando à conclusão de que as personalidades e identidades do coletivo são formadas a partir dessas representações sociais. Segundo Magalhães (2005), a publicidade, ao produzir imagem, som e texto, expressa emoções e relembra princípios da imaginação, estimulando a construção da personalidade, comportamento e identidades do 
coletivo. Igualmente, Kellner (2001) concorda que a mídia utiliza recursos audiovisuais para engajar o público e fazê-lo concordar com certas opiniões e atitudes.

Moreira (2003) e Pollay (1986) concluem que os publicitários são responsáveis pela construção e proliferação de gostos, ideias e atitudes em relação aos indivíduos. Uma vez que a publicidade é uma mensagem repassada através meios de comunicação que utiliza meios visuais e linguísticos para vender produtos e serviços ao público, torna-se um poderoso meio de manipular os indivíduos, influenciando-os a consumir por meio das mídias. (HARVEY, 2000)

Para Hoff e Gabrielli (2004), a comunicação publicitária vai além de vender e divulgar produtos e serviços. Elaborada por especialistas da área, ela é um processo que envolve técnicas que visam influenciar, sensibilizar e cativar o consumidor, tornando-se assim, um dos mais importantes meios de comunicação da sociedade. Veríssimo (2013) ressalta que a publicidade é um meio de representar o coletivo. Da mesma forma em que anseia necessidades aos indivíduos em forma de produtos e serviços, também é uma ferramenta que conscientiza, sensibiliza e educa, a fim de minimizar problemas da sociedade.

Representações sociais por meio da propaganda funcionam da mesma maneira que o produto, e as organizações precisam adaptar seu posicionamento conforme mudanças sociais e de comportamento. Lipovetsky (2004) explora o novo discurso das companhias, visando uma imagem humanizada, empática e moral, respeitando novos valores, colocando em prática atitudes responsáveis, melhorando a imagem da marca. O novo modo de comportamento das empresas aconteceu após os anos 1970 e 1980 e, perante o novo comportamento da audiência da época, tornou necessária a criação de campanhas de narrativas marcantes e relevantes para a sociedade, como sinaliza Carrascoza (2004).

É evidente que, atualmente, as empresas precisam se preocupar com questões sociais e ecológicas de acordo com o que necessita a sociedade na qual a organização está inserida. Ashley (2003) compreende que as grandes organizações e as que pretendem expandir precisam se preocupar também com questões de diversidade cultural, promovendo as exigências de respeito dos direitos humanos e liberdade. Para manter uma boa imagem corporativa perante o público, é imprescindível adotar tais atitudes.

\subsection{Audiovisual}

A propaganda representa o meio social de diversas maneiras e interfere o modo de pensar das pessoas indiretamente, sob a perspectiva do audiovisual, por meio das mídias de massa. Conforme Journot (2005), o conceito de audiovisual envolve toda obra que é composta por imagens e sons. A autora complementa ressaltando que, para ser consumado um produto 
audiovisual, é necessário um canal de comunicação de massa, no qual é possibilitada a transferência de som e imagem.

Ribeiro (2008) diz que, para que a imagem e o som possam ser devidamente compreendidos, é necessário se ter uma linguagem específica, que é captada e configurada pelos sistemas visuais e auditivos do expectador, promovendo, então, uma experiência sensorial. O autor ressalta que, para uma obra ser considerada inteiramente audiovisual, é necessário que haja uma narrativa. Para Genette (1979 apud JOURNOT, 2005), narrativa se conceitua como uma declaração que estabelece um vínculo de um episódio ou vários, e, mesmo que a narração também seja necessária para a história, elas são dessemelhantes, pois não dependem do meio em que vai se dispor em uma narrativa.

De acordo com Ribeiro (2008), a narrativa audiovisual é incorporada pelo ponto de vista do espectador e é composta por significantes que podem ter diferentes sentidos. Se é pela análise da imagem que se pode fazer a leitura, então a imagem não existirá sozinha, apenas através da narrativa como um todo. Ainda neste sentido, Ribeiro (2008) diz que, ao determinar os componentes significantes junto à ajuda das alternativas da linguagem audiovisual, são originados signos e linguagens, sendo verbais ou não, que representam realidades familiares do dia a dia.

Para compreender melhor o audiovisual, Silva (2007) cita a audiovisualidade, que é de característica virtual que se torna moderna e atual quando acompanha produtos audiovisuais à medida que se cria audiovisuais ainda não familiarizados. O audiovisual é formado por vários produtos culturais, tais quais: o cinema, televisão, vídeo games, clipes etc. Cada um deles tem impacto social e história próprios. (HAGEMEYER, 2012) As novas possibilidades audiovisuais fornecidas pelos meios digitais impactam de forma constante a maneira com que o público vem se relacionando com esses meios, fornecendo novas possibilidades para a comunicação. (MÉDOLA; OLIVEIRA, 2016)

Entrando em mídias, Alves, Fontoura e Antoniutti (2012) explicam que o cinema é um dos meios mais estimulantes criados com a finalidade de comunicar, pois, sendo uma mensagem subliminar, ele possibilita inúmeras interpretações, já que tudo depende de sua estrutura audiovisual. Somente o cinema tem a capacidade de proporcionar experiências reais ao público. Seguindo a mesma linha de pensamento, para as autoras, a televisão é um fantástico meio audiovisual, pois trouxe o mundo para o cotidiano da população, com o poder ativo de propagar novos conceitos relativos à sociedade.

Alves, Fontoura e Antoniutti (2012) ressaltam que o surgimento dos meios comuns audiovisuais, como a televisão e o cinema, acarretou novas possibilidades de comunicação e 
remodelaram o conceito de entretenimento na vida das pessoas, assim como o transcende para suas dimensões educacionais, sociais e culturais.

Com a chegada da televisão, foram necessários novos formatos de criação, remodelando os antigos formatos de mensagem. A televisão proporcionou um novo modelo para chamar a atenção do público, agora mais exigente, de forma que a propaganda precisava proporcionar uma ideia para influenciar e persuadir o espectador. Passando para o pensamento da internet, esta é hoje um dos mais importantes meios de comunicação em escala universal, com uma imensa gama de opções de recursos. Da mesma forma, a internet é um meio de oportunidades para o anúncio de produtos e bens e, assim como em qualquer outro meio, também necessita persuadir, engajar, convencer e informar. (ALVES; FONTOURA; ANTONIUTTI, 2012)

\section{Procedimentos metodológicos}

Conseguinte até aqui, esta etapa visa destacar os procedimentos metodológicos, meios de coletas de dados e análise da propaganda “Sophia”, lançada como campanha de Dia das Mães em 2018 pelo Mercado Livre, que conta com mais de 6 milhões de visualizações no YouTube.

Para um estudo mais coerente desta campanha, utiliza-se a pesquisa qualitativa, que, segundo Godoy (1995), tem um lugar muito importante, uma vez que estuda fenômenos que envolvem seres humanos e suas relações com a sociedade. Em concordância, Flick (2009) reflete a pesquisa qualitativa como base para o estudo das relações humanas em torno das questões abrangentes à vida. Este tipo de pesquisa é exploratória, conforme Gil (2007), pois facilita o reconhecimento do problema em estudo com maior familiarização, tornando-o mais compreensível e acessível.

Como procedimento de coleta, utilizou-se a modalidade grupo focal, que favorece a livre expressão, trazendo à tona opiniões, pensamentos e sentimentos do grupo. A principal característica de um rupo focal, de acordo com Morgan (1997 apud GONDIM, 2003), é o diálogo entre os sujeitos do grupo a fim de produzir dados coerentes, levando compreensão e clareza a um determinado tema de forma rápida e clara em curto tempo. Para a proposta deste artigo, foram convidadas dez pessoas, aqui identificados por suas falas como participantes A, B, C, D, E, F, G, H, I, J.

Os(as) participantes foram submetidos a uma entrevista coletiva e semiestruturada, na qual foram propostas questões acerca da importância da representatividade LGBT+ na propaganda "Sophia”. A entrevista semiestruturada é composta por um roteiro com questões abertas e permite que o diálogo flua com mais naturalidade. O roteiro utilizado está contemplado no apêndice deste artigo. Fujisawa (2000) destaca que esta é a forma mais utilizada de entrevista, 
uma vez que proporciona flexibilidade dos questionamentos e dá a possibilidade de ampliação das perguntas à medida que a entrevista se desenvolve.

O intuito da produção de um grupo focal é questionar o público sob suas percepções e opiniões ao se deparar com uma propaganda que retrata formas não convencionais de se representar uma família, e como isso pode influenciar o modo de pensar das pessoas e suas vidas. Assim, faz-se necessário engajar pessoas de diversos gêneros, idades, orientações sexuais e crenças a partir da publicidade.

Para gerir o grupo e alcançar o objetivo do artigo, a líder utilizou uma série de questionamentos $^{6}$ que ajudaram a alcançar de forma correta e objetiva as metas da pesquisa, questionamentos estes que também foram repassados em forma de questionário ao final do grupo focal, buscando compreender de forma pessoal e individual a opinião das pessoas. O debate foi gravado em áudio e vídeo para, assim, posteriormente, ser analisado de forma minuciosa.

A seleção do tema foi feita para compreender a família LGBT+, pois o estereótipo da família tradicional ainda está, em sua maior parte, presente na lembrança do conceito de família. A escolha de uma propaganda se deve pela facilidade que o audiovisual propõe ao sujeito se colocar no lugar do personagem e dispõe aspectos e sensações que são únicos se tratando desse método.

Para concluir, a técnica usada como critério de análise de dados será a análise de conteúdo, pois a esta cabe definir no modo de pesquisa qualitativa e se enquadra da melhor maneira com o desenvolvimento do artigo e a análise de campanha. Análise de conteúdo, de acordo com Olabuénaga e Ispizua (1989), é um método de ler e interpretar registros, o que nos abre a mente para novos aspectos, antes não conhecidos, e para conhecimentos sobre a vida social.

A análise de conteúdo através de um grupo focal foi contemplada pelas seguintes etapas:

1. Preparação das informações: para analisar o conteúdo da melhor forma possível, foi necessária uma leitura e visualização detalhada das informações. O grupo focal foi gravado em vídeo para que, desta forma, posteriormente fossem visualizadas as expressões, falas e diálogos dos participantes. O questionário composto por 15 perguntas e o vídeo foram descritos e juntados por unidades semelhantes com números e cores que pudessem ser separados para a análise.

2. Unitarização ou transformação do conteúdo em unidades: os conteúdos foram separados por categorias; as perguntas feitas ao longo do debate e no questionário facilitaram essa categorização por possuírem o mesmo tema. As perguntas e respostas foram separadas por grau de concordância, igualdade e relevância entre si, sendo classificadas entre: válidas, se são

6 Ver apêndice. 
pertinentes ao tema principal; inconclusivas, se não tiveram relevância ao artigo; ou igualitárias, se as respostas tiveram concordância entre si em sua maioria.

3. Descrição: nesta etapa, realizou-se a descrição e junção das respostas e dados obtidos ao longo da análise do grupo focal. Para facilitar, fez-se uma tabela com as perguntas e respostas coerentes determinadas.

4. Interpretação: as respostas foram reunidas e compreendidas para que pudessem contribuir de forma pertinente a este trabalho, permitindo uma interpretação aprofundada para que cada participante pudesse expressar sua opinião a respeito do tema de forma única.

\section{Análise dos dados}

Este trabalho tem como foco compreender as opiniões e percepções dos(as) participantes do estudo sob o aspecto da propaganda "Sophia”, que é uma campanha de Dia das Mães realizada pelo Mercado livre em 2018. A campanha ressalta as diferentes formas de se constituir uma família, relatando as duas mães de Sophia, com personalidades e necessidades distintas. O comercial evidência Sophia, uma menina comum, realizando atividades corriqueiras com seus amigos, que, em conversa, descrevem os gostos dos seus pais. A personagem relata sua mãe de diferentes formas, parecendo se contradizer, o que causa impacto e estranhamento, visto que ninguém imagina que a personagem tenha uma família constituída por duas mulheres. No final, Sophia se reúne com sua família para comemorar o Dia das Mães e entrega respectivamente seus presentes, revelando que a menina tem duas mães.

No dia 6 de outubro de 2019, às 15h, reunimos o grupo para iniciar a pesquisa com entrevistados, que de forma alguma foram avisados previamente sobre o tema da pesquisa. A atividade ocorreu em um local com uma atmosfera bem intimista (na casa da própria autora). Num primeiro momento, o comercial foi exibido e, em seguida, a moderadora (a própria pesquisadora) levantou uma série de questionamentos, gerando debate de ideias e exposição de opiniões e percepções, momento que foi gravado em vídeo e áudio para ser analisado posteriormente. Ao final do debate, a moderadora entregou um questionário com as mesmas perguntas que ajudaram a mediar a discussão, em que cada pessoa respondeu individualmente. Os convidados serão aqui identificados por suas falas como participantes A, B, C, D, E, F, G, H, I, J.

A análise do comercial foi realizada com um grupo focal constituído por 10 pessoas, sendo seis mulheres e quatro homens, com idades entre 18 e 50 anos, sete heterossexuais, dois homossexuais e um bissexual, com educação formal que varia do ensino superior incompleto ao completo e renda mensal variada. Um pouco mais da metade (seis pessoas) tem religião, e o 
restante se considera ateu. Quanto à identidade étnica do grupo, entre as 10 pessoas, nove são brancos e apenas um é negro. Os questionamentos resultaram em um longo debate, e os pontos importantes da discussão foram destacados de forma a atender aos objetivos da pesquisa.

O primeiro questionamento teve relação direta com opinião central do grupo sobre a propaganda. Ao serem perguntados sobre seus primeiros pensamentos no decorrer do vídeo, os integrantes, em sua maioria, relataram que estavam tentando entendê-lo, estavam confusos quanto à fala da personagem, que estava se contradizendo ao falar de sua mãe, como destaca o participante A: "achei que a personagem mudava de opinião para se sentir pertencente ao grupo” (informação verbal). O participante I também indaga: “Eu estava tentando entender o vídeo, parecia que a menina estava mentindo, só no final eu entendi” (informação verbal).

O grupo também destacou que o vídeo trata a questão da família de forma leve e natural. Ao serem questionados se, ao decorrer da propaganda, já haviam imaginado que Sophia poderia ter duas mães, metade do grupo respondeu que não, como sugere a fala do participante A (informação verbal): “Não pensei nisso. No final ficou óbvio, mas no início não. Estamos poucos acostumados a ter esse tipo de representação, que pegou de surpresa" (informação verbal). Em outro momento, quando perguntados sobre o que mais chamou a atenção no vídeo, o participante G destacou: "Me chamou a atenção que os amigos não procuravam entender ou perguntar a confusão da menina ao descrever as mães, não deram abertura para ela falar sobre, pois claramente eles não sabiam que a menina tinha duas mães” (informação verbal). A fala do participante F também destaca: “Apesar de ter diversos tipos de família, ainda tem a estranheza em vermos esse tipo de família, por isso temos que parar para entender a propaganda" (informação verbal).

Essas questões são explicadas por Berlant e Warner (2002). A sociedade impõe a heterossexualidade como um padrão, como forma coerente de se relacionar, adicionando que leva a heterossexualidade como um privilégio em forma de relação (por não necessitar privar-se do afeto), em diversas estruturas sociais.

\footnotetext{
Por heteronormatividade entendemos aquelas instituições, estruturas de compreensão e orientações práticas que não apenas fazem com que a heterossexualidade pareça coerente - ou seja, organizada como sexualidade - mas também que seja privilegiada. [...] é percebida como um estado natural; também se projeta como um objetivo ideal ou moral. (BERLANT; WARNER, 2002, p. 230)
}

Conseguinte questionamento sobre a opinião do grupo acerca da propaganda, os participantes responderam que o vídeo tem um impacto grande quanto à representatividade e inclusão da família constituída pela união entre pessoas do mesmo gênero. Para o participante H: “A propaganda é ótima, pois mostra que, independente da forma que é a família, a felicidade é 
indiferente em todos os casos” (informação verbal). Conforme ainda outros questionamentos feitos ao grupo sobre a importância dessa representatividade em comerciais televisivos, destacase algumas falas. Conforme participante A: "todas as famílias devem ser representadas, para que uma criança que não tenha uma 'família tradicional' se sinta normal, pois o que é anormal? Isso não existe!” (informação verbal). Em outro momento, a mesma participante (A) fala sobre a representatividade na mídia: “A representatividade impacta em a criança respeitar que existem outros tipos de amor, a pessoa nasce hétero ou gay, e, se ela nascer gay, é importante pra ela, que ela veja que isso é uma coisa natural e não uma aberração” (informação verbal). Outra fala destaca também a representatividade, como é caso da participante D: “Acho que todas [as] formas de família devem ser representadas, principalmente para que se torne mais comum e habitual no dia a dia das pessoas" (informação verbal).

Silva (2000) define representatividade um processo ligado diretamente à composição da identidade e diferença. Ambos são símbolos produzidos culturalmente e que apenas ganham sentido perante a representação, que tem poder de caracterizar o que irá definir o “outro”. A representação é um "sistema linguístico e cultural arbitrário, indeterminado e estreitamente ligado à relação de poder”. (SILVA, 2000, p. 91)

Estes aspectos refletem o quanto é coerente, junto à sociedade, a representação de outros tipos de família e amor. Paiva ressalta que:

\begin{abstract}
No esforço por definir a natureza da atuação dos grupos minoritários e seu papel social, é preciso lembrar que não se trata apenas da mera atuação nas brechas abandonadas pelas instituições [...] o envolvimento efetivo e digno dos indivíduos precisa estabelecer-se sobre o pressuposto da inclusão, da responsabilidade, do afeto e do respeito. (PAIVA, 2009, p. 23)
\end{abstract}

Ao serem perguntados sobre a influência ${ }^{7}$ da propaganda na vida das pessoas, de forma boa ou ruim, e se por algum motivo a propaganda ofende a moral dos indivíduos de algum modo, o participante B indagou: “Alguém pode se ofender, pois sempre há opiniões contrárias, por isso a propaganda traz essa normalidade, uma situação do dia a dia, para mostrar que a única diferença dessa família para uma considerada 'convencional' seria um homem no lugar, ou seja, uma mulher e um homem” (informação verbal). Em concordância, o participante E fala que: “Não influência, pode contribuir de maneira suave, mas não é o que se assiste que se forma uma opinião” (informação verbal). O participante B também ressalta: “Terão 300 propagandas de Dia das Mães, todas essas propagandas vão ter pais e filhos (heterossexuais) comprando presentes. Em apenas uma dessas propagandas vai ter duas mães. De que maneira eu me ofenderia com isso? Pois todo mundo está muito bem representado!” (informação verbal).

7 O termo "influência” referenciado ao longo artigo não significa uma perspectiva funcionalista, que considera o emprego passivo, à mercê da mídia. 
Apesar de todo o grupo concordar que a propaganda não influencia de modo ruim e que não ofende de nenhuma forma, destacando acima de tudo a importância do respeito e a liberdade, todos entraram em comum acordo que algumas pessoas podem ficar ofendidas com a propaganda por questões religiosas como relata o participante G: “Não deveria, porém, grupos religiosos acabam se sentindo atacados, quando, na verdade, o intuito é somente conscientizar a sociedade" (informação verbal). Assim, percebe-se que a religião pode influenciar a maneira de pensar do indivíduo. Entretanto, vale ressaltar que o entrevistado é uma pessoa comum, de forma que a opinião de uma única pessoa não pode ser generalizada. Um dos entrevistados, o participante $C$, segue arduamente a religião (Testemunha de Jeová) e relatou a relação da propaganda com o tema da seguinte forma: “Como comentado, sou religiosa, não aceitamos, mas respeitamos todos os tipos de pessoas" (informação verbal). Sob o mesmo ponto de vista, ao evidenciar sua opinião sobre a importância de representar outras formas de se constituir uma família na propaganda, a mesma participante (C) indagou: “É muito difícil eu assistir alguma propaganda [com personagens LGBT+], mas caso eu tenha que assistir, me sinto incomodada, mas acho importante as pessoas saberem que é importante respeitar todos” (informação verbal).

Conforme Herek (2002), a retórica religiosa é extremamente conservadora e se opõe aos direitos dos homossexuais, condenando tanto a homossexualidade masculina quanto a feminina. Silva (2004) destaca a intolerância como forma de expressar o preconceito:

A intolerância é, portanto, uma das formas de opressão de indivíduos em geral fragilizados por sua condição econômica, cultural, étnica, sexual e até mesmo por fatores etários. Muitas vezes nos surpreendemos ao descobrir a nossa própria intolerância. A construção de uma sociedade fundada em valores que fortaleçam a tolerância mútua exige o estudo das formas de intolerância e das suas manifestações concretas, aliado à denúncia e combate a todos os tipos de intolerância. Por outro lado, a tolerância pressupõe a intransigência diante das formas de intolerância e fundamenta-se numa concepção que não restringe o problema da tolerância! Intolerância ao âmbito do indivíduo; esta é também uma questão social, econômica, política e de classe. (SILVA, 2004, p. 8)

Desta forma, percebe-se que a religião é um empecilho na hora de promover a normatividade homossexual, sobretudo a aceitação das famílias não convencionais, pois, para muitas religiões, é inaceitável uma relação entre pessoas do mesmo gênero.

Ainda discutindo a influência da propaganda na vida das pessoas, todos os participantes concordaram que a propaganda não influencia ideologicamente as pessoas, apenas de forma monetária, pois o interesse da empresa é apenas vender. O participante $\mathrm{H}$ destaca que: “Eu acho que o Mercado Livre está apenas tentando atingir um nicho de mercado e abraçar a causa para tentar vender mais, apesar de ser um assunto importante para se discutir, mas eles estão pensamento no dinheiro” (informação verbal). Em contraponto, o participante D fez a seguinte 
observação: "Pode influênciar de forma leve no sentido de as pessoas começarem a pensar e a questionar mais o assunto, quem sabe pesquisar mais sobre pra ter mais informações a respeito, mas isso não vai fazer ela mudar quem é” (informação verbal). Apesar de concordar com a fala acima, a participante I evidenciou ser importante uma empresa abranger o assunto: “ $A$ propaganda é interessante, eu admiro quando uma empresa escolhe representar outras formas de família e amor" (informação verbal). A relação entre causas sociais e monetárias são explicadas por Peliano (2001): “[...] com essas novas exigências surge a questão da responsabilidade social como fator de competitividade, ou seja, empresas socialmente ativas promovem sua imagem junto aos consumidores, melhoram o relacionamento com as comunidades vizinhas e percebem ganhos de produtividade de seus trabalhadores”. (PELIANO, 2001, p. 33)

Todos os participantes estiveram bastante envolvidos no debate e responderam ao questionário individual de forma coesa. Percebeu-se apenas o silêncio em um dos participantes (J), que em nenhum momento interagiu, apenas concordou várias vezes com a cabeça e, em outros momentos, comentou de forma breve as falas de outros participantes. Ele também não respondeu ao questionário individual.

\section{Considerações finais}

O tema LGBT+ indaga muitas discussões sociais e, neste artigo, foi possível observar variadas opiniões a respeito da propaganda, evidenciando a heteronormatização na sociedade. A mídia tem um grande poder de influência perante a sociedade e, mesmo com interesses monetários, este é um assunto bastante coerente de se tratar nos meios, tanto para a conscientização e normatização social quanto pelo poder de compra de pessoas homossexuais.

Para uma metodologia que pudesse alcançar o intuito genuíno da pesquisa, utilizou-se como instrumento o grupo focal, que pôde ser trabalhado de forma flexível, sendo assim, o assunto foi abordado de forma espontânea, deixando em aberto questões que pudessem indagar a opinião do grupo e pensamentos sobre o tema união homossexual e a formação familiar para alcançar o objetivo da pesquisa.

Os sentidos atribuídos pelo grupo a respeito da propaganda “Sophia” em respeito ao tema (união homossexual e a concretização de uma família) levou a crer que este ainda seja um tema que causa muita controvérsia e contrapontos devido às variadas formas de pensar e aos grupos sociais envolvidos. As falas do grupo estiveram bastante relacionadas, o que pode ter sido um dificultador da pesquisa, pois sabemos que os diferentes grupos envolvidos têm opiniões divergentes por envolver pessoas diferentes, assim, algumas podem ter concordado para não 
gerar outras discussões ou por intimidação. A propaganda evidenciou uma relação de heteronormatividade presente da sociedade, pois a maioria dos entrevistados não imaginou que, ao final da propaganda, Sophia pudesse ter duas mães, o que se deve ao fato também de o comercial abordar a temática LGBT+ de forma leve e corriqueira. A diversidade religiosa presente no grupo também influenciou no debate, destacando distintos modos de pensar, o que fez inclusive com que alguns(as) participantes citaram suas religiões como empecilho da não aceitação a outras sexualidades.

Num aspecto geral, o grupo focal analisou de forma coerente e bastante participativa todas as questões e no debate. Todos(as) os(as) participantes concordaram que a representação social é extremamente importante na mídia, principalmente ao que se refere ao tema central: homossexualidade e família.

Para pesquisas futuras a respeito do tema abordado pela propaganda, a homossexualidade e famílias não convencionais, é interessante retomar a pesquisa do grupo focal analisando a gravação em vídeo, focando em expressões faciais, gestos e postura dos participantes. É importante relatar de forma aprofundada a influência direta da religião com o tema, de forma que se possa detalhar e entender a não aceitação do grupo LGBT+ para os grupos religiosos, mudando opiniões e promovendo a igualdade.

\section{Referências}

ALVES, M. N.; FOnTOURA, M.; ANTONIUTTI, C. L. Mídia $e$ produção audiovisual. Curitiba: Intersaberes, 2012.

ARRUDA, A. Teoria das representações sociais e teorias de gênero. Cadernos de Pesquisa, Rio de Janeiro, n. 117, p. 127-147, 2002.

ASHLEY, P. Ética e responsabilidade social nos negócios. São Paulo: Saraiva, 2003.

BECK, U. A reinvenção da política: rumo a uma teoria da modernização reflexiva. In: BECK, U.; GIDDENS, A.; LASH, S. (org.). Modernização reflexiva: política, tradição e estética na ordem social moderna. São Paulo: Editora Unesp, 1997. p. 11-72.

BERLANT, L.; WARNER, M. Sexo em público. In: JIMÉNEZ, R. M. M. (org). Sexualidades transgressoras: uma antologia de estúdios queer. Barcelona: Içaria, 2002. p. 229-257.

BRAGANÇA, L. Fragmentos da Babadeira História Drag Brasileira. Revista Eletrônica de Comunicação, Informação e Inovação em Saúde, Rio de Janeiro, v. 13, n. 3, p. 527, 2019. 
CARRASCOZA, J. A. Razão e sensibilidade no texto publicitário: como são feitos os anúncios que contam histórias. São Paulo: Futura, 2004.

DIAS, M. B. União homossexual, o preconceito e a justiça. Porto Alegre: Livraria do Advogado, 2005.

FELIPE, J. Representações de gênero, sexualidade e corpo na mídia. Revista Tecnologia e Sociedade, Curitiba, v. 2, n. 3, p. 251-263, 2006.

FLICK, U. Introdução à pesquisa qualitativa. Porto Alegre: Artmed , 2009.

FUJISAWA, S. Utilização de jogos e brincadeiras como recurso no atendimento fisioterapêutico de criança: implicações na formação do fisioterapeuta. 2000. Dissertação (Mestrado em Educação) - Faculdade de Filosofia e Ciências, Universidade Estadual Paulista "Júlio de Mesquita Filho”, Marília, 2000.

GIL, A. C. Como elaborar projetos de pesquisa. São Paulo: Atlas, 2007.

GODOY, A. S. Introdução à pesquisa qualitativa e suas possibilidades. Revista de Administração de Empresas, São Paulo, v. 35, n. 2, p. 57-63, 1995.

GONDIM, G. Grupos focais como técnica de investigação qualitativa: desafio metodológicos. Paidéia, Ribeirão Preto, v. 12, n. 24, p. 149-161, 2003.

HAGEMEYER, R. R. História \& audiovisual. Belo Horizonte: Autêntica, 2012.

HARVEY, D. Condição pós-moderna: uma pesquisa sobre as origens da mudança cultural. São Paulo: Loyola, 2000.

HEREK, G. Gender gaps in public opinion about lesbians and gay men. Oxford: Public Opinion Quarterly, 2002.

HOFF, T.; GABRIELLI, L. Redação publicitária. Rio de Janeiro: Elsevier, 2004.

JOURNOT, M.-T. Vocabulário de cinema. Lisboa: Edições 70, 2005.

KELLNER, D. A cultura da mídia: estudos culturais, identidade e política entre o moderno e o pós-moderno. Bauru: Edusc, 2001.

KOTLER, P.; KELLER, K. L. Administração de marketing. São Paulo: Pearson, 2012.

LIPOVETSKY, G. Metamorfoses da cultura liberal: mídia, ética, empresa. Porto Alegre: Sulina, 2004. 
MARQUES, C. Da esfera cultural à esfera política: a representação de grupos de sexualidade estigmatizada nas telenovelas e a luta por reconhecimento. 2003. Dissertação (Mestrado em Comunicação) Universidade Federal de Minas Gerais, Belo Horizonte, 2003.

MAGALHÃES, I. Análise do discurso publicitário. Revista da Abralin, Campinas, n. 1-2, p. 231-260, 2005.

MÉDOLA, D. L. S. A.; OLIVEIRA, J. B. Audiovisual panorâmico para dispositivos móveis: reconfigurações em tela, imersão e instância narradora. In: ENCONTRO ANUAL DA COMPÓS, 25., 2016, Goiânia. Anais [...]. Brasília, DF: Compós, 2016.

MEDRADO, B. Textos em cena: a mídia como prática discursiva. In: SPINK, J. (org.). Práticas discursivas e produção de sentidos no cotidiano. São Paulo: Cortez, 2000. p. 243-271.

Mercado Livre Dia das Mães 2018 Sophia. Mercado Livre Brasil, [s. l.], 2018. YouTube. Disponível em: https://bit.ly/3aCKIfp. Acesso em: 6 abr. 2019.

MOREIRA, A. S. Cultura midiática e educação infantil. Revista Educação \& Sociedade, Campinas, v. 24, n. 85, p. 1203-1235, 2003.

NAVARRO, P. Uma definição da ordem discursiva midiática. In: MILANEZ, N.; GASPAR, N. R. (org.). A (des)ordem do discurso. São Paulo: Contexto, 2010. p. 79-93.

NOGUEIRA, C. Um novo olhar sobre as relações sociais de gênero: feminismo e perspectivas críticas na psicologia social. Lisboa: Fundação Calouste Gulbenkian, 2001.

NUNAN, A. Homossexualidade: do preconceito aos padrões de consumo. Rio de Janeiro: Caravansarai, 2003.

OLABUÉNAGA, J.; ISPIZUA, M. La descodificación de la vida cotidiana: métodos de investigación cualitativa. Bilbao: Universidad de Deusto, 1989.

OLIVEIRA, A. S.; KNÖNER, S. F. A construção do conceito de gênero: uma reflexão sob o prisma da psicologia. 2005. Trabalho de Conclusão de Curso (Graduação em Psicologia) - Universidade Regional de Blumenau, Blumenau, 2005.

PAIVA, R.; BARBALHO, A. Comunicação e cultura das minorias. São Paulo: Paulus, 2009.

PELIANO, M. T. M. Bondade ou interesse? Como e por que as empresas atuam na área social. Brasília, DF: Ipea, 2001.

POLLAY, R. The distorted mirror: reflections on the unintended consequences of advertising. Journal of Marketing, Thousand Oaks, v. 
50, n. 2, p. 18-36, 1986.

RIBEIRO, A. M. C. A narrativa audiovisual: o cinema e o filme publicitário. 2008. Dissertação (Mestrado em Ciências da Comunicação) - Universidade do Minho, Braga, 2008.

SILVA, A. O. Reflexões sobre a intolerância. São Paulo: Espaço Acadêmico, 2004.

SILVA, A. R. Elementos para uma comunicação pós-midiática. 2007. Dissertação (Mestrado em Ciências da Comunicação) - Universidade do Vale do Rio dos Sinos, São Leopoldo, 2007.

SILVA, T. Identidade e diferença: a perspectiva dos estudos culturais. Petrópolis: Vozes, 2000.

TAVARES, F. Discurso publicitário e consumo: uma análise crítica. Rio de Janeiro: E-Papers, 2005.

THOMPSON, J. B. A mídia e a modernidade: uma teoria social da mídia. Petrópolis: Vozes, 2004.

TREVISAN, J. S. Devassos no paraíso. São Paulo: Max Limonade, 2000.

VERÍSSIMO, F. S. Discurso publicitário da sustentabilidade: um estudo das estratégias persuasivas em anúncios de revista. 2013. Dissertação (Mestrado em Comunicação) - Universidade Federal de Santa Maria, Santa Maria, 2013.

WOODWARD, K. Identidade e diferença: uma introdução teórica e conceitual. In: HALL, S. (org.). Identidade e diferença: a perspectiva dos estudos culturais. Petrópolis: Vozes, 2000. p. 7-72. 


\section{Apêndice}

\section{Roteiro de perguntas}

Para levar adiante esse questionamento, prepara-se um roteiro de entrevista, que deverá ser aplicada aos entrevistados. Nele, encontra-se algumas perguntas pessoais referentes à religião, idade e orientação sexual, por fim, enfatiza-se perguntas referentes à percepção das pessoas a respeito da propaganda "Sophia":

1. Qual é sua idade?

a. ( ) 18 a 28 anos

b. ( ) 28 a 38 anos

c. ( ) 38 a 48 anos

d. ( ) 48 a 68 anos

2. Como você se identifica (gênero)?

a) Masculino

b) Feminino

c) Nenhum

3. Escolaridade:

a. ( ) Ensino fundamental incompleto

b. ( ) Ensino fundamental completo

c. ( ) Ensino médio incompleto

d. ( ) Ensino médio completo

e. ( ) Ensino superior incompleto

f. ( ) Ensino superior completo

4. Qual é sua renda mensal?

5. Você segue alguma religião? Qual?

Periódicus, Salvador, n. 16, v. 3, out.2021-dez.2021 - Revista de estudos indisciplinares em gêneros e sexualidades Publicação periódica vinculada ao Núcleo de Pesquisa NuCuS, da Universidade Federal da Bahia - UFBA ISSN: 2358-0844 - Endereço: http://www.portalseer.ufba.br/index.php/revistaperiodicus 
6. Qual é sua orientação sexual?

7. Qual foi a primeira coisa que você pensou assistindo ao vídeo?

8. O que mais chamou sua atenção no vídeo?

9. Qual é sua opinião sobre a propaganda “Sophia”? Comente um pouco sobre.

10. Antes de revelar o final da propaganda, já havia passado pela sua cabeça que "Sophia” pudesse ter duas mães? Justifique.

11. Quais sensações o vídeo te transmitiu? Descreva até três.

12. A maneira pela qual a propaganda "Sophia" aborda a união homossexual na formação familiar ofende sua moral de alguma forma? Justifique!

13. Qual é sua opinião sobre o tema homossexualidade e família em comerciais televisivos?

14. Você acha importante a propaganda representar outras formas de se constituir uma família? Justifique.

15. Você acredita que representar outras formas de se constituir uma família influencia negativamente as pessoas? Justifique. 